\title{
Female Faculty at Texas 4-Year Public Universities: Changes over Time
}

\author{
Chelsea K. Smith and John R. Slate \\ Department of Educational Leadership, Sam Houston State University, Huntsville, United States \\ Email: profslate@aol.com
}

\begin{abstract}
In this study, the percentages of female faculty at Texas 4-year public universities for the 2003 and 2014 academic years were examined to determine the degree to which changes might have occurred over time. Archival data were retrieved from the Texas Higher Education Coordinating Board on Assistant Professor, Associate Professor, and Full Professor faculty positions at Texas 4year universities. Inferential statistical procedures revealed the presence of statistically significant differences was between the percentages of female faculty in each of the three positions between the 2003 and 2014 academic years. A statistically significant higher percentage of female faculty members was present in the 2014 academic year than in the 2003 academic year. Interestingly, the percentage of female faculty members at the Full Professor position increased by $9.46 \%$ over this time period, compared to an increase of only $4.15 \%$ at the Assistant Professor level, and an increase of only $4.04 \%$ at the Associate Professor level. Based on these percentages increase, female faculty members at the entry level rank of Assistant Professors were not increasing at the same rate as female Full Professors, which indicates a gap in the pipeline of professorship for female faculty. Discussion and policy recommendations to address this gap are discussed in this study.
\end{abstract}

Keywords: Female faculty, assistant professor, associate professor, full professor

\section{Introduction}

Women in leadership has been a hot topic across political arenas in the United States. Women have become top executives at Fortune 500 companies such as Yahoo, they have become front-runners for established political parties, and they are being recognized as elite athletes in sports, like the United States Women's Soccer team. However, race and ethnic diversity initiatives continue to be the main source of concern for many institutions of higher education. Although these initiatives are warranted, attention to gender bias is key for the career advancement of women. Institutions of higher education have a unique opportunity to examine this issue and address inequities that might be present. By doing so, universities could stay ahead of the political and social curve and become a standard of best practice, along with increasing female diversity to be equitable with the United States general population.

\subsection{Purpose}

The purpose of this study was to determine the degree to which female faculty percentages changed from the 2003 to the 2014 academic years at Texas 4-year public universities. Women earn more degrees at higher levels than men earn but are not keeping pace with achieving tenure, senior-level positions, or equal pay (Lepkowski, 2009 \& Ortega-Liston and Soto, 2014). Determined in this investigation was whether the percentages of female faculty members at the three major faculty ranks at Texas 4-year public institutions changed between the 2003 and the 2014 academic years.

\section{$2 \quad$ Background}

In reviewing the literature for this study, three specific areas were identified as barriers for women: gender, ethnicity, and mentorship. In recent studies on gender inequities, Betts and Saurez (2011) stated that despite growing diversity in the U.S. population, minimal diversity is present when examining demographics for female faculty, administrators, and board members Ortega-Liston and Soto (2014) 
analyzed the barriers, choices, and decisions of women faculty in higher education. The results were that women minority groups were not equal with their White counterparts in becoming tenured professors.

Gender, ethnic, social, and institutional structures are a few of the barriers that hinder women form attaining career advancement in higher education. According to the American Association of University Professors (AAUP) 2009-2010 study, women full-time faculty members earn less than their male colleagues at each of the traditional professional ranks; professor, associate professor, and assistant professor (Curtis, 2011). The authors noted that when the salary gap is addressed by administrators, the salary gap tends to be ignored and pushed to the side with little explanation on how to correct the inequity. Stated in another study was that women earn over " $58 \%$ of all bachelor's degrees and $45 \%$ of all doctorates in the United States, however less than $23 \%$ of women are college presidents at institutions of higher education" (Lepkowski, 2009, p. 1). Therefore, women who seek to attain career advancement should be aware of the barriers that exist and be prepared to overcome those challenges. Universities should also be prepared to address these barriers and implement support systems that will assist women with career advancement opportunities.

\subsection{Significance of the Study}

The significance of this study is to provide data for universities to address gaps in the progression of female faculty that might be present. The focus of this study is on the percentages of female faculty who were classified as an Assistant, Associate, or Full Professor at Texas 4-year public universities during the 2003 and 2014 academic years. Universities may be able to utilize this information to recruit, support, and create opportunities toward career advancement for female faculty.

\section{$2.2 \quad$ Research Questions}

The following research questions were addressed in this study: (a) What is the difference in the percentage of female Assistant Professors in Texas 4-year universities between the 2003 and 2014 academic years?; (b) What is the difference in the percentage of female Associate Professors in Texas 4year universities between the 2003 and 2014 academic years?; and, (c) What is the difference in the percentage of female Full Professors in Texas 4-year universities between the 2003 and 2014 academic years?

\section{Method}

\subsection{Participants}

In this study, the following definitions were used according to the Texas Higher Education Coordinating Board (2016): (a) "Assistant Professor, "a faculty member of an institution of higher education who ranks above an instructor and below an associate professor and who is tenured or is on a tenure track" (p. 5); (c) Associate Professor, "a faculty member of an institution of higher education who ranks above an assistant professor and below a professor and who is tenured or is on a tenure track" (p. 5); (d) [Full] Professor, "a faculty member of an institution of higher education who has the highest academic rank and who is tenured or is on-tenure track" (p. 49).

\subsection{Instrumentation and Procedures}

Archival data were retrieved from the Texas Higher Education Coordinating Board Interactive Accountability System and downloaded into an excel format. The information obtained were the percentages of female Assistant professors, female Associate professors, and female Full Professors between the 2003 and 2014 academic years. The data were then recoded and labeled using the Statistical Package for the Social Sciences (SPSS) program which contained the percentages of female faculty in each of the outlined academic years. 


\subsection{Research Design}

A nonexperimental quantitative research design was used for this study. The research was causal comparative which allows the researcher to investigate two or more groups and compare them according to their independent variable which has already occurred (Creswell, 2013). In this study the independent variable was time (i.e., the 2003 through the 2014 academic years). The dependent variable was position (i.e., Assistant, Associate, or Full Professor). Participants were 35 4-year public universities in 2003 and 38 4-year public universities in 2014.

\section{$4 \quad$ Results}

Before conducting inferential statistics to determine whether statistically significant differences were present for females employed in faculty positions in the 2003 and 2014 academic years, checks were conducted to determine the extent to which the data were normally distributed. An examination of the standardized skewness coefficients (i.e., the skewness value divided by its standard error) and the standardized kurtosis coefficients (i.e., the kurtosis value divided by its standard error) revealed large deviations from normality. Nine out of 12 standardized coefficients were far outside the bounds of normality of +/-3 (Onwuegbuzie \& Daniel, 2002).

Because the data for female faculty positions in the 2003 and 2014 academic years were not normally distributed, a nonparametric statistical procedure was utilized (Slate \& Rojas-LeBouef, 2011). Accordingly, a nonparametric Wilcoxon's dependent samples $t$-test (Huck, 2007) was used to address the research questions. A dependent samples t-test was an appropriate inferential statistical procedure to calculate when the variables (i.e., position and time) are related (Slate \& Rojas-LeBouef, 2011). In this investigation, the percentage of faculty members who were female was present for the 2003 and 2014 academic years and were at the interval/ratio level of measurement.

For research question one, the Wilcoxon's dependent samples $t$-test yielded a statistically significant difference in the percentage of female Assistant Professors between the 2003 and 2014 academic years, $z$ $=-1.95, p=.05$. The effect size associated with this difference, Cohen's $d$, was 0.33, small (Cohen, 1988). Female Assistant Professors in Texas 4-year universities had a statistically significant higher percentage in the 2014 academic year than in the 2003 academic year. Presented in Table 1 are the means and standard deviations for female Assistant Professors in the 2003 and 2014 academic years.

Table 1. Descriptive statistics for the percentages of assistant, associate, and full professors who were female in the 2003 and 2014 academic years

\begin{tabular}{l|l|l|l}
\hline Faculty Rank and Academic Year & $n$ of universities & $M \%$ & $S D \%$ \\
\hline Assistant Professor & & & \\
\hline 2003 & 35 & 43.25 & 14.90 \\
\hline 2014 & 38 & 47.40 & 9.29 \\
\hline Associate Professor & & & \\
\hline 2003 & 35 & 34.87 & 11.83 \\
\hline 2014 & 38 & 38.92 & 9.22 \\
\hline Full Professor & & & \\
\hline 2003 & 35 & 19.32 & 9.55 \\
\hline 2014 & 38 & 28.78 & 11.97 \\
\hline
\end{tabular}

Regarding the second research question, a statistically significant difference was present between the 2003 and 2014 academic years, $z=-3.10, p<.002$, in the percentage of female Associate Professors. The effect size associated with this difference, Cohen's $d$, was 0.38, small (Cohen, 1988). The percentage of female Associate Professors in Texas 4-year universities was statistically significantly higher in the 2014 academic year than in the 2003 academic year. Table 1 contains the descriptive statistics for female Associate Professors in the 2003 and 2014 academic years. For the third research question, a statistically 
significant difference was revealed between the 2003 and 2014 academic years, $z=-4.83 p<.001$, in the percentage of female Full Professors. The effect size associated with this difference, Cohen's $d$, was 0.87 , large (Cohen, 1988). The percentage of full professors in Texas 4-year universities who were female was statistically significantly higher in the 2014 academic year than in the 2003 academic year. Descriptive statistics for this analysis are revealed in Table 1.

\section{Discussion}

Revealed in this investigation were statistically significant differences in the percentages of female faculty at the three faculty member ranks. A difference of 4.15\% was present between 2003 and 2014 for female Assistant Professors. Although a small effect size, Cohen's $d$ of 0.33 was associated with this growth, opportunities for female faculty to move into an Assistant Professor were present.The same was true for female Associate Professors as a difference of 4.05\% was present between the 2003 and 2014 academic years, with a small effect size, Cohen's $d$ of 0.38 . The greatest growth occurred in the Full Professor position where a 9.46\% difference was revealed between the 2003 and 2014 academic years, with a large effect size, Cohen's $d$ of 0.87 , over half the amount of the previous two ranks. Increases in the percentages of female faculty between the 2003 and the 2014 academic years show that women are advancing in their careers; however, they are not keeping pace with their male counterparts and it is not reflective of the population as a whole (Lepowski, 2009).

Smith and Crawford (2007) suggested that for women to achieve career advancement successful strategies include not emulating others, establishing power relationships with peers, using persuasive communication, hiring supportive personnel, attending workshops and conferences for networking, establishing a support system, and developing coping skills. They also noted that mentoring is an appropriate strategy for career advancement and those women who have mentor relationships have more satisfaction with their career aspirations. Cox and Salsberry (2012) stated that motivation is an influential factor in determining a woman's decision toward career advancement. This information might explain the lower percentages of female faculty moving from assistant to associate professor. Circumstances such as creating a work-life balance, obligations to family, and the academic pressures of research and tenure may deter female faculty from progressing forward. Bunton, Morrison, Liu, and Dandar (2015) reported that women faculty in the medical field are less likely to report satisfaction with career advancement due to amount of time worked, imbalance of split tasks with male counterparts, and perceptions of colleague respect for work-life balance. Women who seek to progress toward career advancement at the faculty or administrative level should create networking opportunities, develop mentor relationships, and join support groups to assist with self-efficacy, patriarchy, and motivation to pursue career advancement. Universities should create opportunities for women to advance by developing training workshops, participating in active recruitment, utilizing work-life balance policies effectively, and compensating women equally with men. Addressing these inequities will create a more balanced campus culture and be reflective of societal changes.

\section{References}

1. Betts, K., \& Suarez, E. (2011). Career advancement: Ten negotiation strategies for women in higher education. Academic Leadership Journal, 9(3), 1-13.

2. Bunton, A., Morrison, E., Liu, C., \& Dandar, V. (2015, April). Time, effort, and gender disparities in perceptions of advancement among research faculty in U.S. medical schools. Paper presented at the 2015 annual meeting of the American Educational Research Association. Chicago, IL. The AERA Online Paper Repository.

3. Cohen, J. (1988). Statistical power analysis for the behavioral sciences (2nd ed.). Hillsdale, NJ: Lawrence Erlbaum.

4. Cox, K. S., \& Salsberry, T. (2012). Motivational factors influencing women's decisions to pursue upper-level administrative positions at land grant institutions. Advancing Women in Leadership, 32, 1-23.

5. Creswell, J. W. (2013). Qualitative inquiry \& research design: Choosing among the five approaches (3rd ed.). Thousand Oaks, CA: Sage. 
6. Curtis, J. W. (2011, April 11). Persistent inequity: Gender and academic employment. Lecture presented at "New Voices in Pay Equity." https://www.aaup.org/NR/rdonlyres/08E023AB-E6D8-4DBD-99A024E5EB73A760/0/persistent_inequity.pdf

7. Huck, S. W. (2007). Reading statistics and research (5th ed.). New York, NY: Addison Wesley.

8. Lepkowski, C. (2009). Gender and the career aspirations, professional assets, and personal variables of higher education administrators. Advancing Women in Leadership, 29(6), 1-15.

9. Onwuegbuzie, A. J., \& Daniel, L. G. (2002). Uses and misuses of the correlation coefficient. Research in the Schools, 9(1), 73-90.

10.Ortega-Liston, R., \& Soto, I. R. (2014). Challenges, choices, and decisions of women in higher education: A discourse on the future of Hispanic, Black, and Asian members of the professoriate. Journal of Hispanic Higher Education, 13(4), 285-302. doi:10.1177/1538192714540531

11.Slate, J. R., \& Rojas-LeBouef, A. (2011). Calculating basic statistical procedures in SPSS: A self-help and practical guide to preparing theses, dissertations, and manuscripts. Ypsilanti, MI: NCPEA Press.

12.Smith, D. T., \& Crawford, K. (2007). Climbing the ivory tower: Recommendations for mentoring African American women in higher education. Race, Gender \& Class, 14(1-2), 253-265.

13.Texas Higher Education Coordinating Board. (2016). Accountability section. Retrieved from http://www.txhighereddata.org/Interactive/Accountability/ 